\title{
Altered colonic sensory and barrier functions by CRF: roles of TLR4 and IL-1
}

\author{
Tsukasa Nozu', Saori Miyagishi², Rintaro Nozu', Kaoru Takakusaki³ and Toshikatsu Okumura²,4 \\ 1Department of Regional Medicine and Education, Asahikawa Medical University, Asahikawa, Hokkaido, Japan \\ 2Division of Gastroenterology and Hematology/Oncology, Department of Medicine, Asahikawa Medical University, Asahikawa, Hokkaido, Japan \\ ${ }^{3}$ Research Center for Brain Function and Medical Engineering, Asahikawa Medical University, Asahikawa, Hokkaido, Japan \\ ${ }^{4}$ Department of General Medicine, Asahikawa Medical University, Asahikawa, Hokkaido, Japan
}

Correspondence should be addressed to T Nozu: tnozu@sea.plala.or.jp

\section{Abstract}

Visceral allodynia and increased colonic permeability are considered to be crucial pathophysiology of irritable bowel syndrome (IBS). Corticotropin-releasing factor (CRF) and immune-mediated mechanisms have been proposed to contribute to these changes in IBS, but the precise roles have not been determined. We explored these issues in rats in vivo. The threshold of visceromotor response, i.e., abdominal muscle contractions induced by colonic balloon distention was electrophysiologically measured. Colonic permeability was estimated by quantifying the absorbed Evans blue in colonic tissue. Intraperitoneal injection of CRF increased the permeability, which was blocked by astressin, a non-selective CRF receptor antagonist, but astressin ${ }_{2}-B$, a selective CRF receptor subtype $2\left(\mathrm{CRF}_{2}\right)$ antagonist did not modify it. Urocortin 2, a selective $\mathrm{CRF}_{2}$ agonist inhibited the increased permeability by CRF. Eritoran, a toll-like receptor 4 (TLR4) antagonist or anakinra, an interleukin-1 receptor antagonist blocked the visceral allodynia and the increased gut permeability induced by CRF. Subcutaneous injection of lipopolysaccharide (immune stress) or repeated water avoidance stress (WAS, psychological stress), $1 \mathrm{~h}$ daily for 3 days induced visceral allodynia and increased gut permeability (animal IBS models), which were also blocked by astressin, eritoran or anakinra. In conclusion, stress-induced visceral allodynia and increased colonic permeability were mediated via peripheral CRF receptors. CRF induced these visceral changes via TLR4 and cytokine system, which were $\mathrm{CRF}_{1}$ dependent, and activation of $\mathrm{CRF}_{2}$ inhibited these $\mathrm{CRF}_{1}$-triggered responses. CRF may modulate immune system to alter visceral changes, which are considered to be pivotal pathophysiology of IBS.

Key Words
- corticotropin-releasing
factor
- cytokine
- gut permeability
- toll-like receptor 4
- visceral pain

Journal of Endocrinology (2018) 239, 241-252

\section{Introduction}

Irritable bowel syndrome (IBS) is a functional gastrointestinal (GI) disorder characterized by the presence of chronic abdominal pain with altered bowel habits without any organic cause (Mearin et al. 2016). Stress alters colonic sensorimotor function and has a significant impact on the development and exacerbation of IBS symptoms (Taché et al. 2009). Since exogenous administration of corticotropin-releasing factor (CRF) mimics these colonic functional changes, and CRF antagonist abolishes these responses to stress (Taché et al. 2009, Nozu \& Okumura 2015), CRF is considered to be a key molecule in the pathophysiology of IBS. 
The actions of CRF are mediated through the activation of two receptors, CRF receptor subtypes $1\left(\mathrm{CRF}_{1}\right)$ and 2 $\left(\mathrm{CRF}_{2}\right)$ (Perrin \& Vale 1999, Hillhouse \& Grammatopoulos 2006). Classically, increased colonic contractility and visceral hypersensitivity induced by CRF were considered to be exclusively mediated through the activation of $\mathrm{CRF}_{1}$ (Taché et al. 2009). However, we previously demonstrated that these functional changes were $\mathrm{CRF}_{1}$ dependent indeed, but activating $\mathrm{CRF}_{2}$ suppressed these $\mathrm{CRF}_{1}$-triggered responses, and the signaling balance of $\mathrm{CRF}_{1}$ and $\mathrm{CRF}_{2}$ may determine these colonic functional changes (Nozu et al. 2014). According to these results, we advocated the balance theory of peripheral $\mathrm{CRF}_{1}$ and $\mathrm{CRF}_{2}$ signaling (Nozu et al. 2014, Nozu \& Okumura 2015).

There is ample evidence that compromised gut barrier function manifested by increased gut permeability is observed in the patients with IBS (Taché et al. 2009). Stress is also known to increase gut permeability, which is mediated via CRF (Santos et al. 1999, 2008, Overman et al. 2012, Yu et al. 2013). However, the precise role of CRF receptor subtypes on gut permeability has not been determined, and both $\mathrm{CRF}_{1}$ and $\mathrm{CRF}_{2}$ have been reported to increase gut permeability (Barreau et al. 2007, Gareau et al. 2007, Teitelbaum et al. 2008, Ayyadurai et al. 2017). Moreover, it is not known whether this change follows the balance theory of CRF signaling.

Impaired gut barrier induces bacterial translocation resulting in increased lipopolysaccharide (LPS) and proinflammatory cytokine, which is also thought to be an important aspect of IBS (Barbara et al. 2012, Dlugosz et al. 2015, Nozu et al. 2017b). Actually, plasma proinflammatory cytokine and serum LPS are increased in IBS (Dinan et al. 2006, Ortiz-Lucas et al. 2010, Scully et al. 2010, Dlugosz et al. 2015). Moreover, LPS-induced stimulation of cytokine release from peripheral blood mononuclear cells is enhanced in this disease, and higher symptoms severity such as urgency, diarrhea, etc., are associated with higher cytokine response induced by LPS (Liebregts et al. 2007). Since LPS is a ligand of toll-like receptor 4 (TLR4), these results suggest that activating TLR4-cytokine signaling may contribute to the visceral functional changes in IBS.

We have recently demonstrated that injection of LPSor repeated water avoidance stress (WAS)-induced visceral allodynia was interleukin (IL)-1 and IL-6-dependent response, and peripheral CRF signaling also mediated this change possibly by modulating the cytokine release in rats (Nozu et al. 2017b,c). Additionally, peripheral administration of LPS upregulates CRF ligands in colon, and LPS-induced cytokine response is mediated via peripheral CRF receptor (Yuan et al. 2016). In this context, it may be considered that peripheral CRF alters visceral sensation and gut permeability via modulating TLR4 and cytokine signaling. However, there has been no study to ascertain this notion definitely, especially in vivo.

In this study, we explored the roles of peripheral CRF receptor subtypes and immune system such as TLR4 and cytokine on visceral sensation and gut permeability in vivo and tried to confirm the link between CRF and TLR4, cytokine signaling. In addition, the roles were also evaluated on these altered visceral changes induced by LPS (immune stress) or repeated WAS (psychological stress), which are considered to be experimental animal models of IBS (Larauche et al. 2012, Nozu et al. $2017 a, b, c)$.

\section{Materials and methods}

\section{Animals}

Adult male Sprague-Dawley rats (Charles River Laboratories) weighing about $300 \mathrm{~g}$ were used. The animals were housed groupwise (3-4 rats/cage) under controlled conditions of illumination (12-h light/darkness cycle starting at 07:00 h) with temperature regulated at $23-25^{\circ} \mathrm{C}$. Rats were allowed free access to standard food (Solid rat chow, Oriental Yeast, Tokyo, Japan) and tap water.

\section{Chemicals}

A rat/human CRF (Peptide Institute Inc., Asagi, Japan), human urocortin 2, a selective $\mathrm{CRF}_{2}$ agonist (Bachem AG, Bubendorf, Switzerland), LPS obtained from Escherichia coli with the serotype 055:B5 (Sigma-Aldrich) and anakinra, an IL-1 receptor antagonist (Swedish Orphan Biovitrum, Stockholm, Sweden) were dissolved in normal saline. Astressin, a non-selective CRF receptor antagonist, astressin $_{2}-\mathrm{B}$, a selective $\mathrm{CRF}_{2}$ antagonist (Sigma-Aldrich) and cortagine, a selective $\mathrm{CRF}_{1}$ agonist (PolyPeptide Laboratories, Torrance, CA, USA) were dissolved in double-distilled water. The doses of the chemicals were determined according to the previous reports (Santos et al. 1999, Nozu et al. 2017b,c). The volume of injection was $0.2 \mathrm{~mL} / \mathrm{rat}$. Additionally, eritoran tetrasodium, a TLR4 antagonist (a kind gift from Eisai Inc., Andover, MA, USA) was dissolved in PBS with the concentration of $3.5 \mathrm{mg} / \mathrm{mL}$. LPS was subcutaneously injected. Other drugs were administered via intraperitoneal route. 


\section{Measuring colonic permeability}

Colonic permeability measurement was performed as previously described (Nozu et al. 2017a). The rats anesthetized by administration of the mixture of medetomidine hydrochloride (Orion Pharma Ltd., Dhaka, Bangladesh, $0.15 \mathrm{mg} / \mathrm{kg}$ ), midazolam (Sandoz, Tokyo, Japan, $2 \mathrm{mg} / \mathrm{kg}$ ) and butorphanol tartrate (Meiji Seika Pharma, Tokyo, Japan, $2.5 \mathrm{mg} / \mathrm{kg}$ ) intraperitoneally were placed in a supine position on a heating pad, and laparotomy was performed. The colon was ligated at the junction with the cecum, and a small hole was made at $1 \mathrm{~cm}$ from the ileocecal junction by a puncture using $18 \mathrm{G}$ needle. Then, an open-tipped catheter (3-Fr, Atom, Tokyo, Japan) was inserted into the proximal colon through the hole and fixed by purse-string sutures. The colon was gently flushed with $\mathrm{PBS}\left(37^{\circ} \mathrm{C}\right)$ using the catheter until all stools were washed out. Normally, the required volume of PBS was less than $10 \mathrm{~mL}$ and the perfusion rate was $5 \mathrm{~mL} / \mathrm{min}$. Later, another ligation was added on the colon at approximately $4 \mathrm{~cm}$ from the proximal one, and $1 \mathrm{~mL}$ of 1.5\% Evans blue in PBS was instilled into the colon through the catheter. The animals were killed after $15 \mathrm{~min}$, and the colons were excised. Later, they were washed with PBS and $1 \mathrm{~mL}$ of $6 \mathrm{mM} \mathrm{N}$-acetyl-cysteine and were opened and placed in $2 \mathrm{~mL}$ of $\mathrm{N}$, N-dimethylformamide for $12 \mathrm{~h}$. The permeability was calculated by measuring the Evans blue concentration in the supernatant using a spectrophotometer at $610 \mathrm{~nm}$.

\section{Measuring visceral sensation}

Visceral sensation was assessed by abdominal muscle contractions induced by colonic distention (visceromotor response (VMR)) using electromyogram (EMG) in conscious rats, which was validated as quantitative measure of visceral nociception (Ness \& Gebhart 1988).

\section{Implantation of electrodes and placement of colonic distention balloon}

Under brief ether anesthesia, a small skin incision was made in non-fasted rats and electrodes (Teflon coated stainless steel, $0.05 \mathrm{~mm}$ diameter, MT Giken, Tokyo, Japan) for EMG were inserted approximately $2 \mathrm{~mm}$ into left side external oblique musculature through the incision. They were fixed to musculature by cyanoacrylate instant adhesive together with the incised skin. The electrode leads were externalized directly through this closed incision without a subcutaneous tunnel and threaded through a urethane tube. Neither analgesics nor antibiotics were administered after the surgery. Distension balloon (6-Fr disposable silicon balloon-urethral catheter, JU-SB0601, Terumo Corporation, Tokyo, Japan) was inserted intra-anally with the distal end positioned $2 \mathrm{~cm}$ proximal to the anus. The volume and length of maximally inflated balloon were $1.5 \mathrm{~mL}$ and $1.2 \mathrm{~cm}$.

\section{Colonic distention and measuring abdominal muscle contractions}

After completing electrode implantation and balloon placement, the rats were placed in Bollmann cages and acclimated to the experimental condition for $30 \mathrm{~min}$ before testing. Later, the electrode leads were connected to an EMG amplifier, and EMG signals were amplified, filtered $(3000 \mathrm{~Hz})$, digitized by a PowerLab system (AD Instruments, Colorado Springs, CO, USA) and recorded using computer software (LabChart 7, AD Instruments). Colonic distension was performed according to a previous publication (Nozu et al. 2017a), namely, ascending method of limits phasic distension was applied in increments of $0.1 \mathrm{~mL}$ for $5 \mathrm{~s}$ by inflating the balloon by water using a syringe manually until significant abdominal muscle contractions, i.e., VMR were detected (Fig. 1A). The VMR threshold was defined as the distended balloon volume $(\mathrm{mL})$ inducing VMR. The threshold was measured twice (2-min interval), and the threshold mean was calculated as the data of the animals. The percentage change threshold, i.e., the threshold value after treatment divided by the basal threshold value and multiplied by 100 , was calculated.

\section{Experimental protocols}

The basal VMR threshold was measured, and then the electrodes and distention balloon were removed followed by administration of the vehicle or drug ('Injection', Fig. 1B). Ten minutes later, the vehicle or CRF was injected, and the rats were returned to their home cages. At $3.5 \mathrm{~h}$ later, the rats underwent surgery for electrode implantation and balloon placement again, and the second measurement of threshold was performed at $4 \mathrm{~h}$ after the injection followed by the measurement of colonic permeability (Fig. 1B). This protocol was decided according to the previous study demonstrating that intraperitoneal CRF $(50 \mu \mathrm{g} / \mathrm{kg})$ increased gut permeability with maximal response at $4 \mathrm{~h}$ after the injection in rats (Santos et al. 1999).

For evaluating the effect of LPS, the second measurement of threshold was performed at $3 \mathrm{~h}$ after the injection (Fig. 1C). We previously confirmed that 
A

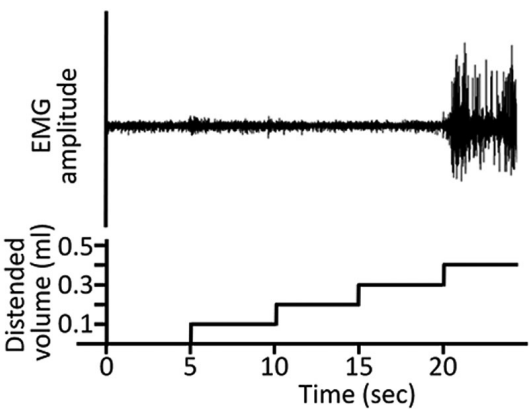

B

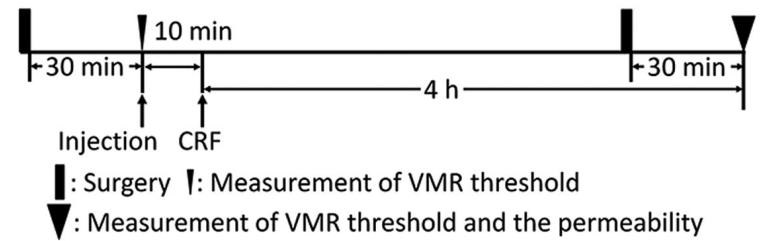

C
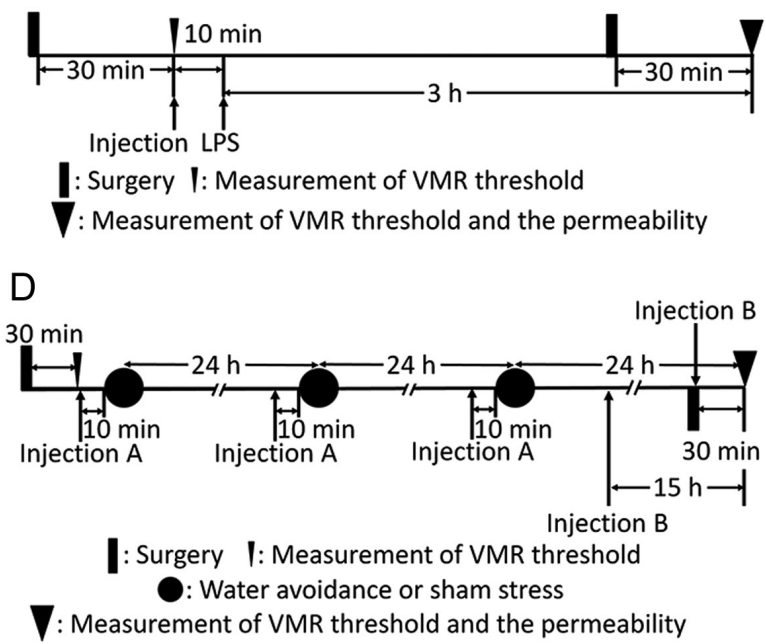

Figure 1

(A) The threshold of visceromotor response (VMR) was determined by the distended balloon volume $(\mathrm{mL})$ inducing apparent sustained abdominal muscle contractions detected by electromyogram (EMG). The threshold was $0.4 \mathrm{~mL}$ in this animal. (B) Schematic representation of the experimental protocol. The basal VMR threshold was measured at $30 \mathrm{~min}$ after the surgery for implanting EMG electrodes and placing the balloon, then the vehicle or drug was injected (Injection). Ten min later, the vehicle or CRF was injected, and the second measurement of threshold was performed at $4 \mathrm{~h}$ after the injection followed by measuring colonic permeability. (C) The protocol evaluating the mechanism of LPS-induced visceral changes. The basal VMR threshold was measured, and vehicle or drug was injected (Injection). Ten min later, the vehicle or LPS was injected and the visceral changes were evaluated at $3 \mathrm{~h}$ after the injection. (D) The protocol regarding repeated water avoidance stress. The basal threshold was measured, and the rats were subjected to either water avoidance or sham stress for $1 \mathrm{~h}$ daily for three consecutive days. The measurement of second threshold and colonic permeability were performed at $24 \mathrm{~h}$ after undergoing the last stress session. The vehicle, astressin or urocortin 2 (Injection A) was injected 3 times at 10 min prior to each stress session. The vehicle, eritoran or anakinra (Injection B) was administered twice at $15 \mathrm{~h}$ and $30 \mathrm{~min}$ before the measurement of second threshold of VMR.

(C) 2018 Society for Endocrinology Published by Bioscientifica Ltd. Printed in Great Britain
LPS $(1 \mathrm{mg} / \mathrm{kg})$ injected subcutaneously induced visceral allodynia at $3 \mathrm{~h}$ after the injection (Nozu et al. 2017b).

For repeated WAS (Fig. 1D), the basal threshold of VMR was measured, and 10 min later, either WAS or sham stress was applied for $1 \mathrm{~h}$. This daily stress session was implemented for three consecutive days. The threshold was again measured at $24 \mathrm{~h}$ after undergoing the last stress session followed by the measurement of colonic permeability. This protocol was demonstrated successfully to induce visceral allodynia in rats (Nozu et al. 2017c). In this model, astressin or urocortin 2 (Injection $\mathrm{A}$ ) was injected at $10 \mathrm{~min}$ prior to each stress session, i.e., injected 3 times. Anakinra or eritoran (Injection B) was administered at $30 \mathrm{~min}$ and $15 \mathrm{~h}$ before the second measurement of the threshold.

\section{Stress procedure}

Exposure to WAS was performed as previously described (Martínez et al. 1997). Rats were individually placed on a plastic platform (height, $8 \mathrm{~cm}$; length, $6 \mathrm{~cm}$; width, $6 \mathrm{~cm}$ ) positioned in the middle of a plastic cage filled with water up to $7 \mathrm{~cm}$ of the platform height. Control animals were individually placed in the same plastic cage, which was not filled with water (sham stress).

\section{Statistical analysis}

Data are expressed as means \pm standard error. Multiple comparisons were performed by two-way ANOVA followed by Tukey's honestly significant difference test. Comparisons between two groups were performed using Student's $t$-test. The SYSTAT 13 software (Systat Software, Chicago, IL, USA) was used for the study.

\section{Ethical considerations}

Approval by the Research and Development and Animal Care Committees at the Asahikawa Medical University (\#15132, approved on April 1, 2015) was obtained for all studies.

\section{Results}

\section{The roles of CRF receptor subtypes on colonic} permeability

Intraperitoneal CRF $(50 \mu \mathrm{g} / \mathrm{kg})$ significantly increased colonic permeability (Fig. 2A). Cortagine $(50 \mu \mathrm{g} / \mathrm{kg})$, a selective $\mathrm{CRF}_{1}$ agonist also increased (Fig. 2B), but urocortin 2 


\begin{tabular}{l|l|l|r|c|}
$\begin{array}{l}\text { Journal of } \\
\text { Endocrinology }\end{array}$ & T Nozu et al. & $\begin{array}{l}\text { CRF alters visceral sensation and } \\
\text { gut barrier }\end{array}$ & $\mathbf{2 3 9 : 2}$ & $\mathbf{2 4 5}$ \\
\hline
\end{tabular}

A
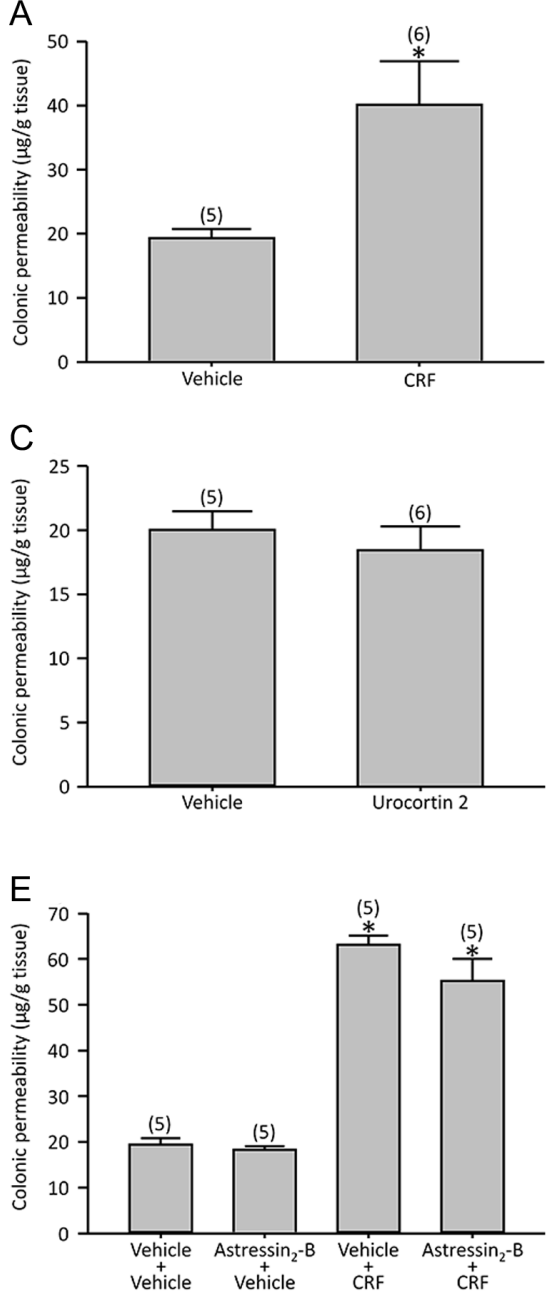

B
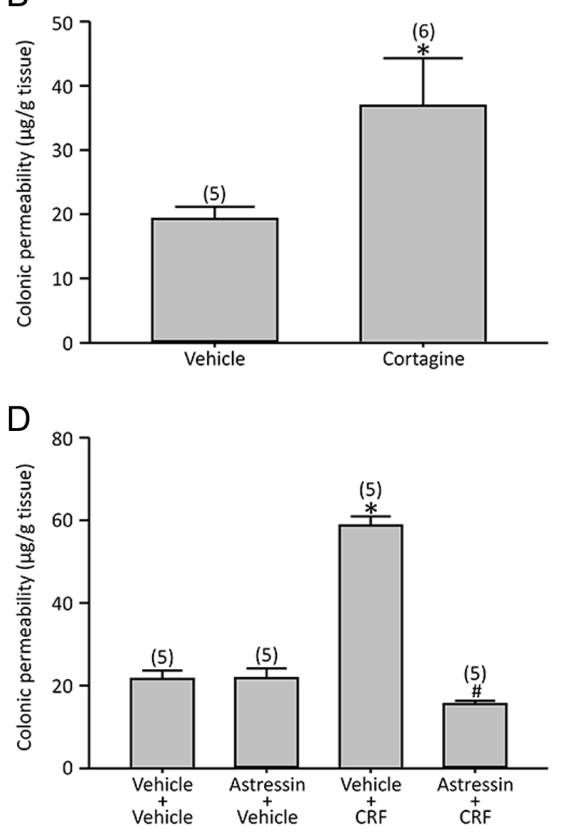

$\mathrm{F}$

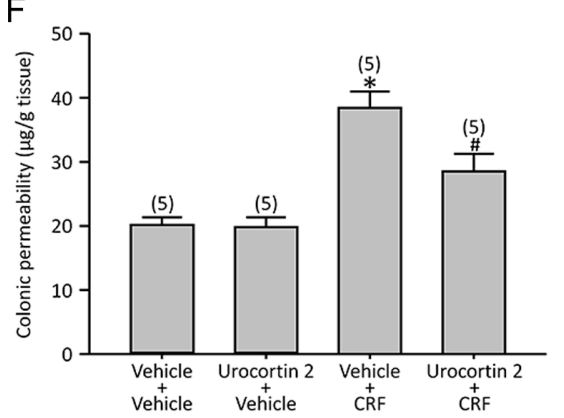

Figure 2

The effects of CRF receptor agonists and antagonists on colonic permeability. CRF $(50 \mu \mathrm{g} / \mathrm{kg})$ increased the permeability (A), and a selective $\mathrm{CRF}_{1}$ agonist, cortagine $(50 \mu \mathrm{g} / \mathrm{kg})$ also increased it (B). Selective $\mathrm{CRF}_{2}$ activation by urocortin 2 $(50 \mu \mathrm{g} / \mathrm{kg})$ did not alter the permeability (C). This change by CRF was abolished by astressin $(200 \mu \mathrm{g} / \mathrm{kg})$, a non-selective CRF receptor antagonist (D), while astressin ${ }_{2}-B(200 \mu \mathrm{g} / \mathrm{kg})$, a selective $\mathrm{CRF}_{2}$ antagonist did not modify it (E). Urocortin 2 attenuated this change by CRF (F). ${ }^{*} P<0.05$ vs vehicle, or vehicle + vehicle, ${ }^{P} P<0.05$ vs vehicle + CRF by two-way analysis of variance followed by Tukey's honestly significant difference test. Each column represents the mean \pm standard error. The number of rats examined is shown in parentheses.
$(50 \mu \mathrm{g} / \mathrm{kg})$, a selective $\mathrm{CRF}_{2}$ agonist did not alter it (Fig. 2C). Astressin $(200 \mu \mathrm{g} / \mathrm{kg})$, a non-selective CRF receptor antagonist blocked the $\mathrm{CRF}$-induced increased permeability (effect of CRF: $F=61.6, P<0.05$, effect of astressin: $F=120.6, P<0.05$, interaction between $C R F$ and astressin: $F=121.9, P<0.05$; Fig. 2D), while astressin ${ }_{2}-\mathrm{B}$ $(200 \mu \mathrm{g} / \mathrm{kg})$, a selective $\mathrm{CRF}_{2}$ antagonist did not alter it (effect of CRF: $F=219.5, P<0.05$, effect of astressin $_{2}$-B: $F=2.7, P>0.05$, interaction between $C R F$ and astressin $_{2}-\mathrm{B}$ : $F=1.58, P>0.05$; Fig. 2E). Urocortin 2 per se did not modify the basal permeability but inhibited the increased permeability by CRF (effect of CRF: $F=24.9, P<0.05$, effect of urocortin 2: $F=8.91, P<0.05$, interaction between $\mathrm{CRF}$ and urocortin 2: $F=8.44, P<0.05$; Fig. $2 F)$. These results indicate that CRF increased colonic permeability, which was $\mathrm{CRF}_{1}$ dependent and activating $\mathrm{CRF}_{2}$ suppressed this response. We already have shown that visceral hypersensitivity by CRF followed similar rules to these changes of colonic permeability (Nozu et al. 2014).

\begin{tabular}{|lr}
\hline https://joe.bioscientifica.com & @ 2018 Society for Endocrinology \\
https://doi.org/10.1530/JOE-18-0441 & Published by Bioscientifica Ltd. \\
Printed in Great Britain
\end{tabular}

The roles of TLR4 and cytokine signaling on CRF-induced visceral changes

CRF induced visceral allodynia, which was blocked by eritoran $(10 \mathrm{mg} / \mathrm{kg})$, a TLR4 antagonist (effect of CRF: $F=14.5, \quad P<0.05$, effect of eritoran: $F=18.3, \quad P<0.05$, interaction between CRF and eritoran: $F=17.8, P<0.05$; Fig. 3A). Moreover, the drug also reversed increased colonic permeability by CRF (effect of CRF: $F=16.6, P<0.05$, effect of eritoran: $F=29.4, P<0.05$, interaction between $C R F$ and eritoran: $F=29.7, P<0.05$; Fig. 3B).

In addition, anakinra $(20 \mathrm{mg} / \mathrm{kg})$, an IL-1 receptor antagonist abolished these visceral changes induced by CRF (\% change threshold, effect of CRF: $F=17.1, P<0.05$, effect of anakinra: $F=29.7, P<0.05$, interaction between CRF and anakinra: $F=25.5, P<0.05$; Fig. 3C, colonic permeability, effect of CRF: $F=9.85, P<0.05$, effect of anakinra: $F=12.2, P<0.05$, interaction between $\mathrm{CRF}$ and anakinra: $F=10.5, P<0.05$; Fig. 3D). 


\begin{tabular}{l|l|l|r|r|}
$\begin{array}{l}\text { Journal of } \\
\text { Endocrinology }\end{array}$ & T Nozu et al. & $\begin{array}{l}\text { CRF alters visceral sensation and } \\
\text { gut barrier }\end{array}$ & $\mathbf{2 3 9 : 2}$ & $\mathbf{2 4 6}$ \\
\hline
\end{tabular}

A

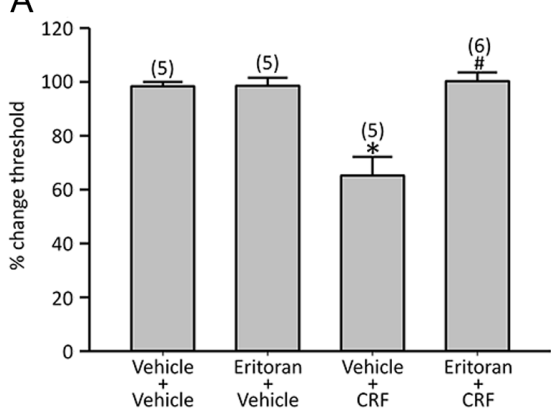

C

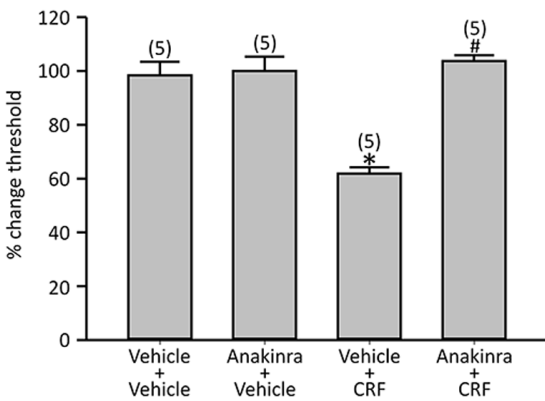

$\mathrm{B}$

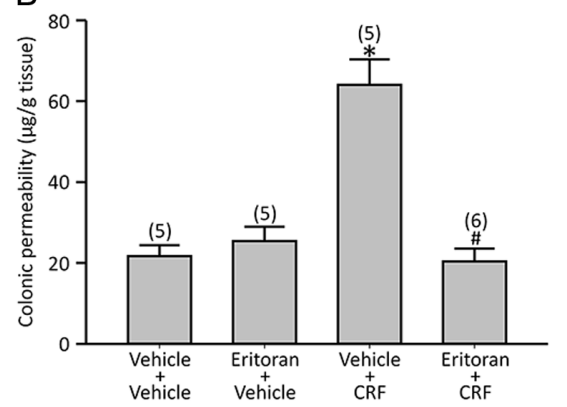

D

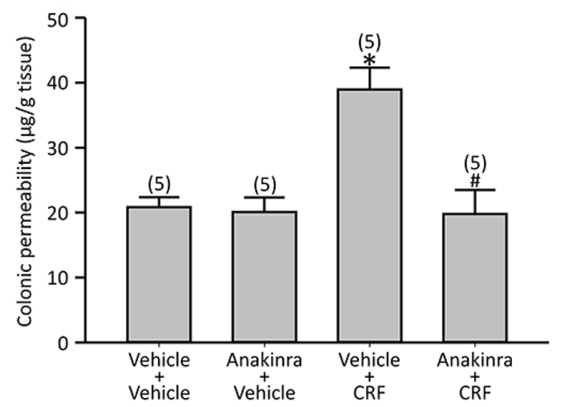

\section{Figure 3}

The roles of toll-like receptor 4 (TLR4) and cytokine on CRF-induced visceral allodynia and increased colonic permeability. Eritoran $(10 \mathrm{mg} / \mathrm{kg})$ fully reversed CRF-induced visceral allodynia (A) and increased colonic permeability (B). In addition, anakinra $(20 \mathrm{mg} / \mathrm{kg})$ also blocked these changes (C and $D)$. ${ }^{*} P<0.05$ vs vehicle + vehicle, $\# P<0.05$ vs vehicle + CRF by two-way analysis of variance followed by Tukey's honestly significant difference test. Each column represents the mean \pm standard error. The number of rats examined is shown in parentheses.

\section{The roles of CRF receptor subtypes on}

\section{stress-induced increased colonic permeability}

LPS $(1 \mathrm{mg} / \mathrm{kg})$ increased gut permeability, and astressin $(200 \mu \mathrm{g} / \mathrm{kg})$ inhibited this response without affecting the basal gut permeability (effect of LPS: $F=12.9, P<0.05$, effect of astressin: $F=10.2, P<0.05$, interaction between LPS and astressin: $F=13.2, P<0.05$; Fig. 4A). Additionally, urocortin $2(50 \mu \mathrm{g} / \mathrm{kg})$ abolished the LPS-induced response (effect of LPS: $F=57.1, P<0.05$, effect of urocortin 2: $F=26.5, P<0.05$, interaction between LPS and urocortin 2: $F=27.9, P<0.05$; Fig. 4B).

Similar results were also obtained in repeated WASinduced increased permeability, i.e., astressin $(50 \mu \mathrm{g} / \mathrm{kg})$ injected $10 \mathrm{~min}$ before each stress session abolished the response (effect of WAS: $F=25.3, P<0.05$, effect of
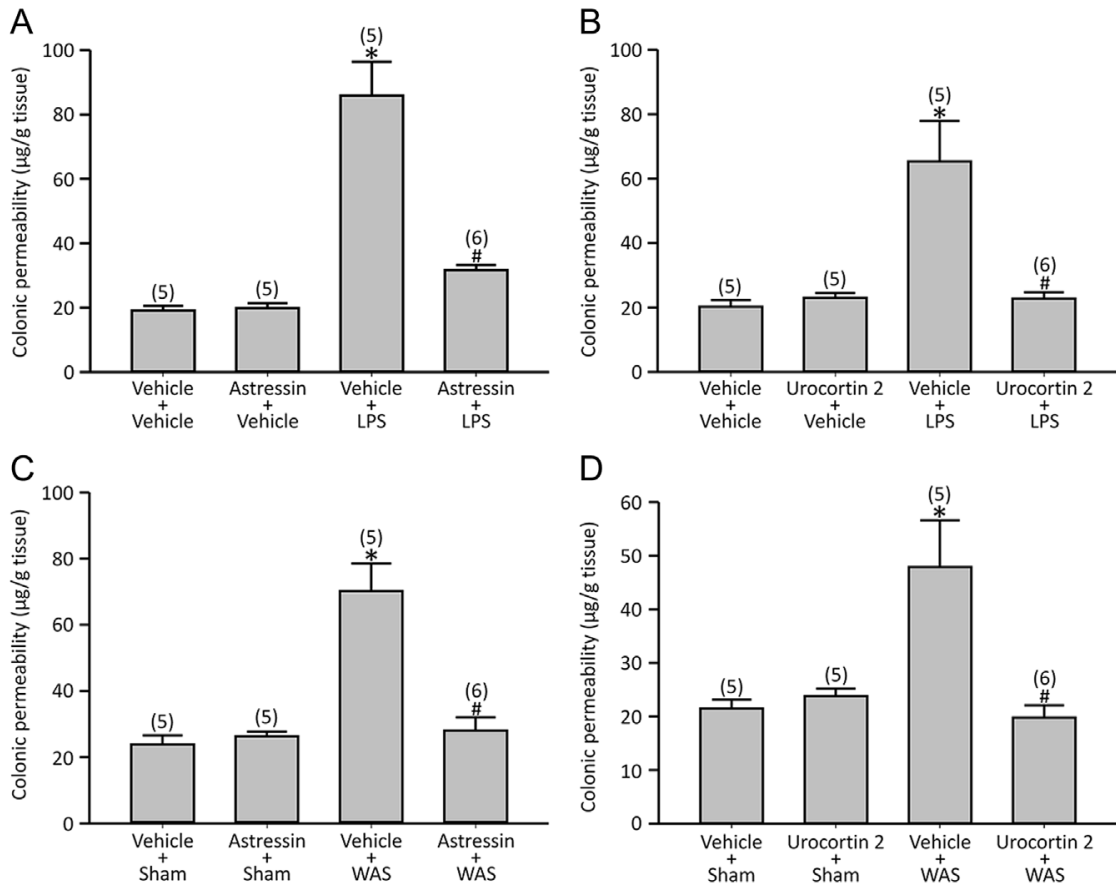

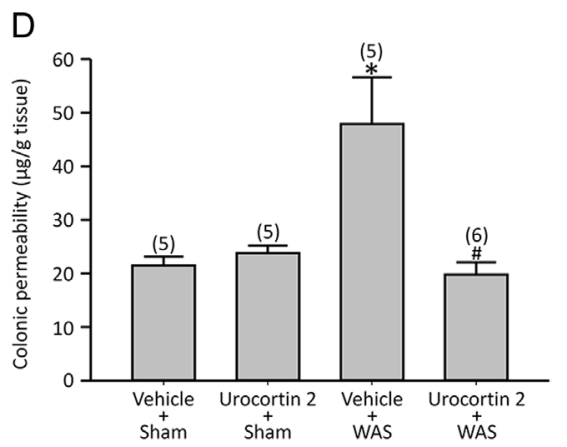

Figure 4

Effect of astressin or urocortin 2 on increased colonic permeability induced by LPS ( $1 \mathrm{mg} / \mathrm{kg}$ ) injection or repeated water avoidance stress (WAS). Astressin $(200 \mu \mathrm{g} / \mathrm{kg})$ or urocortin $2(50 \mu \mathrm{g} / \mathrm{kg})$ blocked the response by LPS (A, B). Besides, the repeated injections of astressin $(50 \mu \mathrm{g} / \mathrm{kg})$ or urocortin $2(50 \mu \mathrm{g} / \mathrm{kg})$ before each stress session also abolished the increased permeability by repeated WAS (C, D). Sham; sham stress. * $P<0.05$ vs. vehicle + vehicle or vehicle + sham, \#P<0.05 vs. vehicle + LPS or vehicle + WAS by two-way analysis of variance followed by Tukey's honestly significant difference test. Each column represents the mean \pm standard error. The number of rats examined is shown in parentheses. 
astressin: $F=17.2, \quad P<0.05$, interaction between WAS and astressin: $F=21.8, P<0.05$; Fig. $4 \mathrm{C}$ ), and urocortin 2 $(50 \mu \mathrm{g} / \mathrm{kg})$ also blocked it (effect of WAS: $F=6.18, P<0.05$, effect of urocortin 2: $F=8.29, P<0.05$, interaction between WAS and urocortin 2: $F=11.5, P<0.05$; Fig. $4 \mathrm{D}$ ).

\section{The roles of TLR4 and cytokine signaling on stress-induced visceral changes}

LPS $(1 \mathrm{mg} / \mathrm{kg})$ reduced the threshold of VMR, and eritoran $(10 \mathrm{mg} / \mathrm{kg}$ ) reversed this response (effect of LPS: $F=7.64$, $P<0.05$, effect of eritoran: $F=15.9, P<0.05$, interaction between LPS and eritoran: $F=17.3, P<0.05$; Fig. 5 A). The increased permeability by LPS was also blocked by eritoran (effect of LPS: $F=27.2, P<0.05$, effect of eritoran: $F=23.6$, $P<0.05$, interaction between LPS and eritoran: $F=24.1$, $P<0.05$; Fig. 5B). Similar effects of eritoran were also found in repeated WAS model. The antagonist fully reversed the reduced threshold (effect of WAS: $F=5.48, P<0.05$, effect of eritoran: $F=8.62, P<0.05$, interaction between WAS and eritoran: $F=6.89, P<0.05$; Fig. $5 C$ ) and the increased permeability (effect of WAS: $F=7.43, P<0.05$, effect of eritoran: $F=11.0, P<0.05$, interaction between WAS and eritoran: $F=10.8, P<0.05$; Fig. 5D) by WAS.

Anakinra $(20 \mathrm{mg} / \mathrm{kg})$ inhibited the increased permeability both induced by LPS (effect of LPS: $F=26.9$, $P<0.05$, effect of anakinra: $F=6.05, P<0.05$, interaction between LPS and anakinra: $F=6.36, P<0.05$; Fig. 5E) and repeated WAS (effect of WAS: $F=20.5, P<0.05$, effect of anakinra: $F=11.1, P<0.05$, interaction between WAS and anakinra: $F=8.85, P<0.05$; Fig. $5 F$ ). We have already shown that visceral allodynia observed in these animal models was abolished by anakinra (Nozu et al. 2017b,c).

\section{Discussion}

Visceral hypersensitivity is considered to be the most important mechanism and a hallmark of IBS (Kanazawa et al. 2011), which may be mediated by CRF receptors
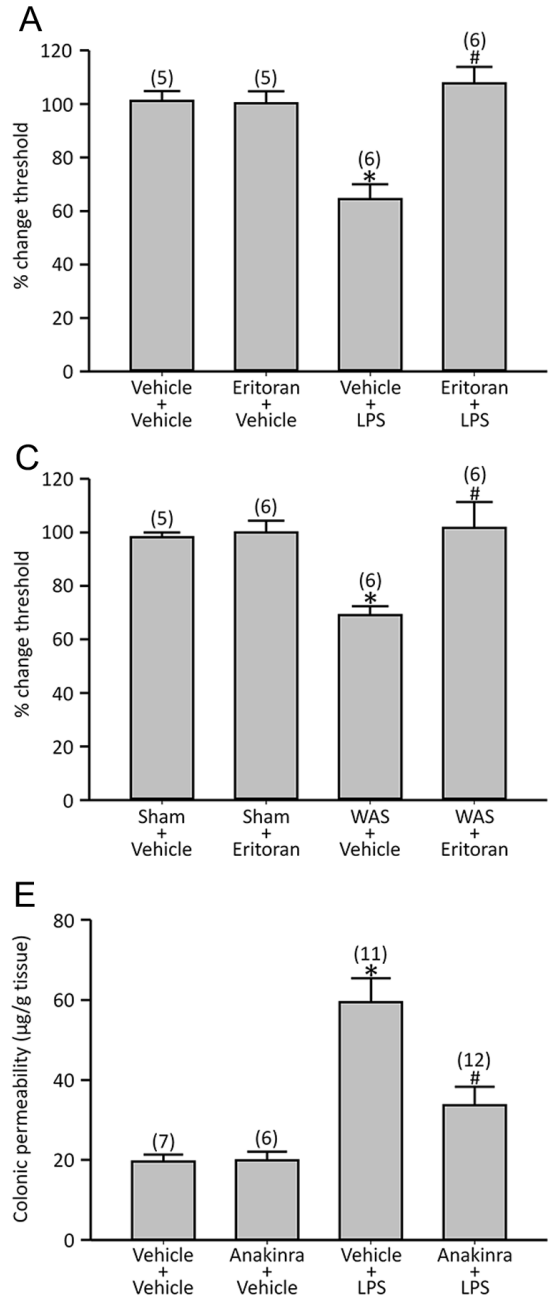

B
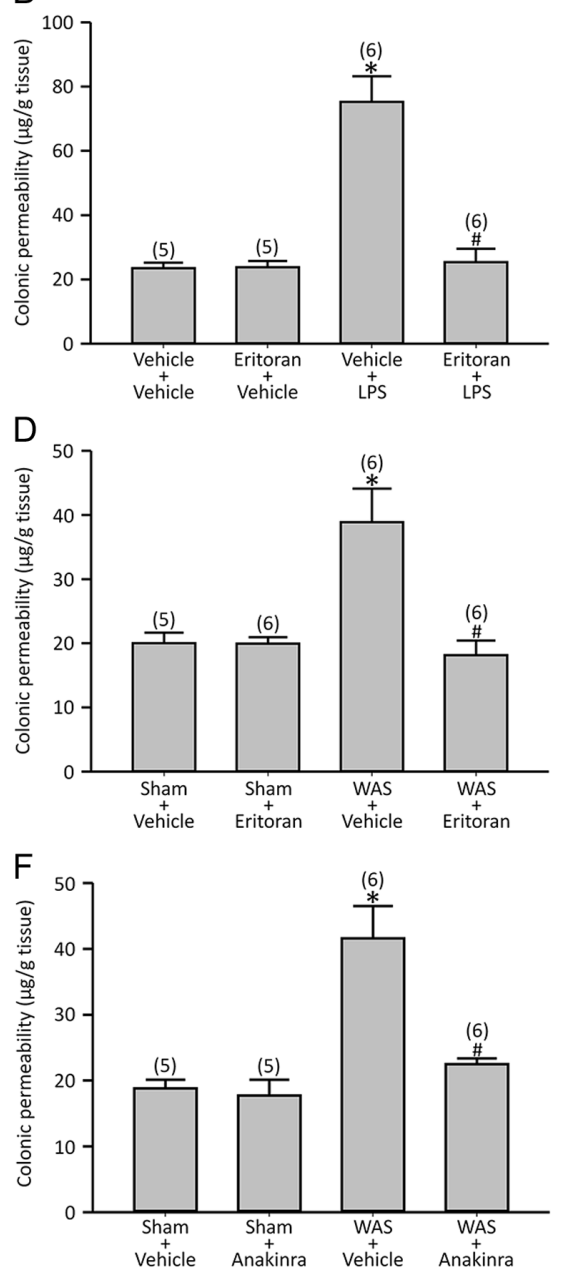

Figure 5

Roles of toll-like receptor 4 (TLR4) and cytokine on stress-induced visceral changes. Eritoran $(10 \mathrm{mg} / \mathrm{kg})$ blocked the allodynia (A) and the increased permeability (B) by LPS. The drug also abolished water avoidance stress (WAS)-induced these visceral changes ( $C$ and $D$ ). Anakinra $(20 \mathrm{mg} / \mathrm{kg}$ ) attenuated the increased permeability induced by LPS (E) or repeated WAS (F). Sham; sham stress. ${ }^{*} P<0.05$ vs vehicle + vehicle or sham + vehicle, $\# P<0.05$ vs vehicle + LPS or WAS + vehicle by two-way analysis of variance followed by Tukey's honestly significant difference test. Each column represents the mean \pm standard error. The number of rats examined is shown in parentheses. 
(Taché et al. 2004). As described before, classically visceral hypersensitivity was considered to be induced exclusively via $\mathrm{CRF}_{1}$. However, recently, inhibitory effects of $\mathrm{CRF}_{2}$ signaling on $\mathrm{CRF}_{1}$-triggered colonic functional changes including visceral hypersensitivity have been shown. Colorectal distention-induced visceral hyperalgesia or intraperitoneal CRF-induced defecation was blocked by peripheral administration of urocortin 2 (Million et al. 2006, Gourcerol et al. 2011, Nozu et al. 2014). Then, we previously have shown that both CRF receptor subtypes were involved, and the signaling balance of $\mathrm{CRF}_{1}$ and $\mathrm{CRF}_{2}$ determined the changes of visceral sensation and colonic contractility, i.e., balance theory of peripheral CRF signaling (Nozu et al. 2014).

The activity balance of each CRF receptor subtype signaling during stress may depend on the released peptides such as CRF and CRF-related peptides, urocortins (urocortin 1, 2 and 3), and their relative affinity for each CRF receptor subtype (Vaughan et al. 1995, Lewis et al. 2001, Reyes et al. 2001). Additionally, expression profile of CRF receptor subtypes of GI tract may also determine the balance. CRF receptors were up or downregulated by stress, and the expression profile of CRF receptor subtypes was changed dynamically (O'malley et al. 2010, Yuan et al. 2010, 2016). Moreover, dominant expression of CRF receptor subtypes varies along the GI tract (Liu et al. 2010, Yuan et al. 2012).

The role of impaired gut permeability has been recently postulated in IBS pathophysiology (Taché et al. 2009). Several studies showed that CRF ligands increased gut permeability and endogenous CRF-mediated stressinduced impaired gut barrier function (Santos et al. 1999, 2008, Larauche et al. 2009, Overman et al. 2012, Yu et al. 2013). Most of these studies were performed in vitro, using colonic cell line (Yu et al. 2013, Yue et al. 2017) or gut segment by Ussing chamber (Santos et al. 1999, 2008, Overman et al. 2012). On the other hand, Larauche et al. showed that peripheral injection of selective $\mathrm{CRF}_{1}$ agonist, cortagine increased colonic permeability in vivo in rats (Larauche et al. 2009), but the precise roles of CRF receptor subtypes have not been determined. Both $\mathrm{CRF}_{1}$ and $\mathrm{CRF}_{2}$ have been reported to increase gut permeability (Barreau et al. 2007, Gareau et al. 2007, Teitelbaum et al. 2008, Ayyadurai et al. 2017).

Current study clearly showed that exogenous peripheral CRF increased colonic permeability in vivo, which was $\mathrm{CRF}_{1}$ dependent. Moreover, activating $\mathrm{CRF}_{2}$ per se did not alter the permeability but suppressed this $\mathrm{CRF}_{1}$-triggered change. Additionally, endogenous CRF also mediated this visceral change induced by LPS or repeated WAS (animal IBS model), which was suppressed by the activation of $\mathrm{CRF}_{2}$. In this context, increased colonic permeability by both exogenous and endogenous CRF may also follow the balance theory of CRF signaling. Since we previously have shown that the quite similar roles of $\mathrm{CRF}_{1}$ and $\mathrm{CRF}_{2}$ signaling on gastric contractility (Nozu et al. 2013), the balance theory might be a fundamental rule in the GI functional changes induced by peripheral CRF.

Whereas we demonstrated inconsistent result with the balance theory, i.e., astressin ${ }_{2}-\mathrm{B}$ did not enhance the increased colonic permeability by CRF. The blocking $\mathrm{CRF}_{2}$ would further enhance $\mathrm{CRF}_{1}$ signaling activated by CRF and increase the permeability. There is the fact of the predominant expression of functional $\mathrm{CRF}_{1}$ relative to $\mathrm{CRF}_{2}$ in colonic myenteric neurons in guinea pig suggesting that $\mathrm{CRF}_{1}$ is the dominant signaling in colon (Liu et al. 2010), which may lead to induce strong activation of $\mathrm{CRF}_{1}$, and consequently, inhibition of $\mathrm{CRF}_{2}$ signaling could not enhance it. Additionally, the dose of CRF $(50 \mu \mathrm{g} / \mathrm{kg})$ used in the study was known to induce maximal response on colonic permeability (Santos et al. 1999), and such strong activation of $\mathrm{CRF}_{1}$ signaling may not permit further enhancement by blocking $\mathrm{CRF}_{2}$.

The mechanisms of $\mathrm{CRF}_{1}$ and $\mathrm{CRF}_{2}$ interaction have not been determined. Gourcerol et al. (2011) showed that peripheral injection of CRF increased defecation and activated colonic myenteric neurons, and these responses were inhibited by activation of peripheral $\mathrm{CRF}_{2}$. Furthermore, the authors also demonstrated that CRF-induced phosphorylation of extracellular signalregulated kinase in primary cultures of the neurons and cyclic adenosine monophosphate production in human embryonic kidney-293 cells transfected with CRF receptors were $\mathrm{CRF}_{1}$ dependent, and $\mathrm{CRF}_{2}$ suppressed the changes. These results suggest that activation of $\mathrm{CRF}_{2}$ inhibits the increased concentration of second messenger and the phosphorylation state of protein kinases leading to inhibiting activation of target cells, thereby suppressing the $\mathrm{CRF}_{1}$-triggered colonic functional changes.

This system of peripheral CRF signaling may be suitable for the survival of organisms under stressful condition. Acute stress induces integrated responses to maintain homeostasis via $\mathrm{CRF}_{1}$, which may be favorable for survival of organisms. However, if the stress response is led into an overdrive state, it can become fatal (Chrousos 2009). Therefore, existence of counter regulatory action by $\mathrm{CRF}_{2}$ signaling could inhibit maladaptation to stress. Moreover, the balance theory suggests that CRF signaling might be shifted toward $\mathrm{CRF}_{1}$ resulting in altered visceral 
functions in IBS, and resetting abnormal CRF signaling balance by blocking $\mathrm{CRF}_{1}$ or stimulating $\mathrm{CRF}_{2}$, may become a promising therapeutic approach to the disease (Nozu \& Okumura 2015).

As described before, TLR4 (LPS)-proinflammatory cytokine system is thought to be involved in the pathophysiology of some portion of IBS patients (Dinan et al. 2006, Ortiz-Lucas et al. 2010, Scully et al. 2010, Dlugosz et al. 2015). TLR4 in colonic tissue of IBS patients is elevated (Kocak et al. 2016), and TLR4 messenger RNA expression in colonic mucosa correlates significantly with duration of symptoms in the IBS patients (Belmonte et al. 2012). In animal studies, WAS significantly increased colonic TLR4 expression (Nebot-Vivinus et al. 2014). Additionally, He et al. showed that chronic stress-induced diarrhea with increased colonic expression of TLR4

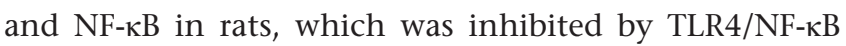
inhibitor (He et al. 2017). Since our current and previous studies showed that the visceral changes observed in our tested animal models were mediated via peripheral CRF, TLR4 and cytokine (Nozu et al. 2017b,c), the existence of the link between CRF and TLR4-cytokine system was expected.

In the current study, we clearly demonstrated for the first time that peripheral exogenous or endogenous CRF-induced visceral allodynia and increased colonic permeability, which were mediated via TLR4 and cytokine signaling in vivo. The mechanisms of these visceral changes induced by peripheral CRF have not been determined definitely so far. Since CRF receptors are proved to be expressed in dorsal root ganglia (Million et al. 2006), CRF may act directly to the receptors to alter visceral sensation. Additionally, enterochromaffin or mast cells have CRF receptors and release chemical mediators, such as serotonin, cytokines etc. (Wu et al. 2011, Overman et al. 2012), which may also contribute to the changes through activating visceral afferents (Mawe et al. 2006, Barbara et al . 2007) and altering tight junction proteins that regulate gut-epithelial barrier (Piche 2014). Our results indicated that CRF may modulate TLR4 and cytokine signaling to alter visceral function, which is a novel mechanism of visceral changes induced by peripheral CRF.

Several studies showed that CRF altered TLR4cytokine signaling. CRF increases the expression of TLR4 on macrophage and enhances the cytokines production by LPS (Tsatsanis et al. 2006). Additionally, colonic TLR4 expression is reduced in CRF-deficient mice (Chaniotou et al. 2010). Incidentally, enterochromaffin and mast cells were reported to have functional TLR4 to secrete chemical mediators including cytokine (McCurdy et al. 2001, Kidd et al. 2009). Since these cells having CRF receptors possibly contribute to visceral changes induced by CRF as described before, the link between CRF and TLR4-cytokine signaling might also occur in these cells. Further studies are needed to explore the precise mechanisms of link between these signaling on visceral changes.

Figure 6 depicted the schematic illustration of the speculated peripheral mechanisms of increased gut permeability and visceral hypersensitivity in IBS regarding peripheral CRF, TLR4 and proinflammatory cytokines. CRF is released from various cells such as neuronal, enterochromaffin and immune cells (mast cells, lymphocytes, etc.) in the colon (Nozu \& Okumura 2015). CRF-CRF $F_{1}$ signaling is thought to be a key factor in IBS (Taché et al. 2009), and CRF signaling balance is abnormally shifted toward $\mathrm{CRF}_{1}$ according to the balance theory (Nozu \& Okumura 2015). CRF activates TLR4 signaling, which triggers to produce proinflammatory

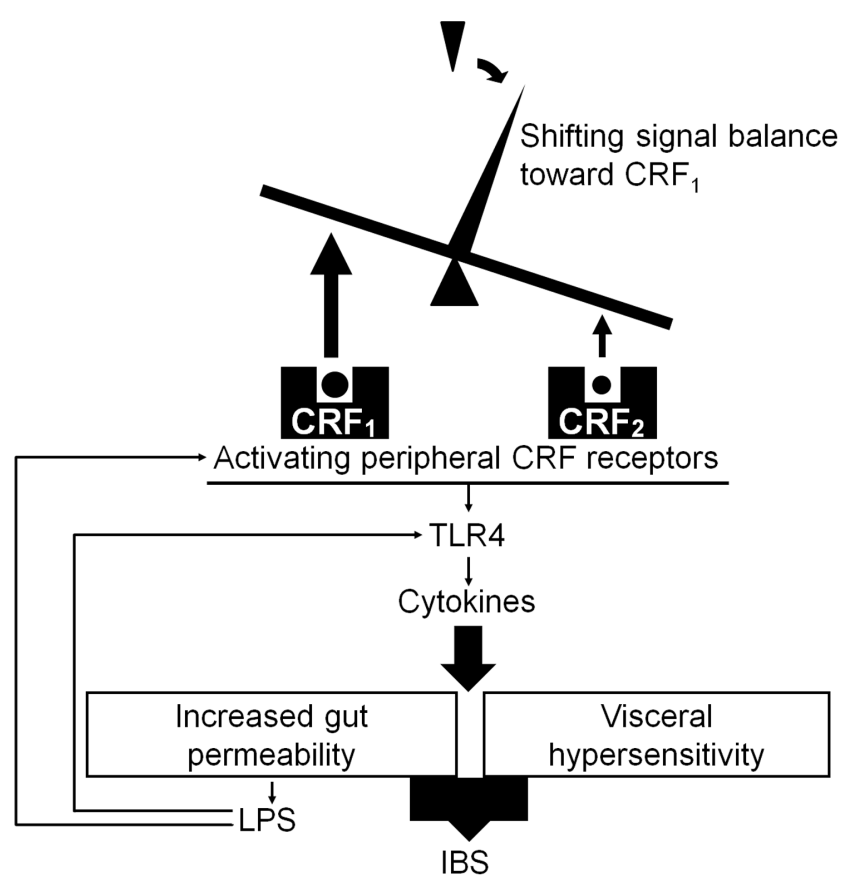

Figure 6

Schematic illustration of our hypothesis in terms of peripheral CRF, toll-like receptor 4 (TLR4) and proinflammatory cytokine on visceral hypersensitivity and increased gut permeability in IBS (peripheral mechanisms). CRF signaling are activated (Taché et al. 2009) and its signaling balance is abnormally shifted toward $\mathrm{CRF}_{1}$ (Nozu \& Okumura 2015). CRF activates TLR4 to trigger producing proinflammatory cytokines, which increases the permeability (Suzuki et al. 2011) and induces visceral hypersensitivity (Obreja et al. 2002). Incidentally, increased gut permeability activates immune system to release LPS. LPS not only stimulates TLR4 but also activates peripheral CRF signaling (Nozu et al. 2017b). In this context, CRF and TLR4-cytokine signaling are considered to form a vicious cycle to activate each other to induce these visceral changes in IBS. 
cytokines, thereby increasing the colonic permeability via modifying tight junction proteins (Suzuki et al. 2011) and inducing visceral hypersensitivity by activating sensory neurons (Obreja et al. 2002).

Increased gut permeability induces bacterial translocation, resulting in activation of immune system leading to inflammation. In this process, LPS is released and proinflammatory cytokines are also produced through the activation of TLR4 by LPS (Dlugosz et al. 2015). Incidentally, LPS is also known to increase CRF messenger RNA in the rat colon (Yuan et al. 2010) and to activate peripheral CRF signaling (Nozu et al. 2017b), which further stimulates TLR4-cytokine system. In this context, peripheral CRF and activation of TLR4-cytokine system may form a vicious circle to activate each other.

The current study had several limitations. Our method required minor surgery, which is inevitable for assessing visceral sensation by EMG. However, it might have some influence on the immune system, which could modify the results. The cellular mechanisms of CRF were not evaluated. Since the targets of peripheral CRF have not been determined definitely so far, we have to explore this issue in the first place. CRF or CRF antagonists used in this study have poor penetrance into brain (Taché \& Brunnhuber 2008), but LPS is known to increase the permeability of blood-brain barrier (Ghosh et al. 2014). Thus, the possibility that peripheral administration of CRF agonists or antagonists act to brain inducing the visceral changes was not completely denied. Further studies were needed to evaluate these issues.

In summary, stress-induced visceral allodynia and increased colonic permeability were mediated via peripheral CRF pathway. CRF induced these visceral changes possibly via TLR4-cytokine system, which were $\mathrm{CRF}_{1}$ dependent, and activation of $\mathrm{CRF}_{2}$ inhibited these $\mathrm{CRF}_{1}$-triggered responses. CRF may modulate immune system to alter visceral changes, which are considered to be pivotal pathophysiology of IBS.

\section{Declaration of interest}

The authors declare that there is no conflict of interest that could be perceived as prejudicing the impartiality of the research reported.

\section{Funding}

This work was partially supported by Japan Society for the Promotion of Science KAKENHI, Grant-in-Aid for Scientific Research (C) (26460287 (T N) and 26460955 (T O)), Scientific Research on Innovative Areas (26120012 (K $\mathrm{T})$ ), and the research grant from the Akiyama Life Science Foundation (T N).

\section{Author contribution statement}

$\mathrm{T} N$ designed and performed the experiment, analyzed the data and wrote the paper; S M and R N performed the experiment; K T contributed to establishing the experimental system monitoring visceral sensation; $\mathrm{T} \mathrm{O}$ designed the experiment, analyzed the data and was involved in critical revision of the manuscript.

\section{Acknowledgment}

Authors wish to thank Eisai Inc. for providing eritoran tetrasodium.

\section{References}

Ayyadurai S, Gibson AJ, D'Costa S, Overman EL, Sommerville LJ, Poopal AC, Mackey E, Li Y \& Moeser AJ 2017 Frontline science: corticotropin-releasing factor receptor subtype 1 is a critical modulator of mast cell degranulation and stress-induced pathophysiology. Journal of Leukocyte Biology 102 1299-1312. (https:// doi.org/10.1189/jlb.2HI0317-088RR)

Barbara G, Wang B, Stanghellini V, de Giorgio R, Cremon C, Di Nardo G, Trevisani M, Campi B, Geppetti P, Tonini M, et al. 2007 Mast celldependent excitation of visceral-nociceptive sensory neurons in irritable bowel syndrome. Gastroenterology 132 26-37. (https://doi. org/10.1053/j.gastro.2006.11.039)

Barbara G, Zecchi L, Barbaro R, Cremon C, Bellacosa L, Marcellini M, De Giorgio R, Corinaldesi R \& Stanghellini V 2012 Mucosal permeability and immune activation as potential therapeutic targets of probiotics in irritable bowel syndrome. Journal of Clinical Gastroenterology 46 (Supplement) S52-S55. (https://doi.org/10.1097/ MCG.0b013e318264e918)

Barreau F, Cartier C, Leveque M, Ferrier L, Moriez R, Laroute V, Rosztoczy A, Fioramonti J \& Bueno L 2007 Pathways involved in gut mucosal barrier dysfunction induced in adult rats by maternal deprivation: corticotrophin-releasing factor and nerve growth factor interplay. Journal of Physiology 580 347-356. (https://doi.org/10.1113/ jphysiol.2006.120907)

Belmonte L, Beutheu Youmba S, Bertiaux-Vandaele N, Antonietti M, Lecleire S, Zalar A, Gourcerol G, Leroi AM, Dechelotte P, Coeffier M, et al. 2012 Role of toll like receptors in irritable bowel syndrome: differential mucosal immune activation according to the disease subtype. PLOS ONE 7 e42777. (https://doi.org/10.1371/journal. pone.0042777)

Chaniotou Z, Giannogonas P, Theoharis S, Teli T, Gay J, Savidge T, Koutmani Y, Brugni J, Kokkotou E, Pothoulakis C, et al. 2010 Corticotropin-releasing factor regulates TLR4 expression in the colon and protects mice from colitis. Gastroenterology 139 2083-2092. (https://doi.org/10.1053/j.gastro.2010.08.024)

Chrousos GP 2009 Stress and disorders of the stress system. Nature Reviews: Endocrinology 5 374-381. (https://doi.org/10.1038/ nrendo.2009.106)

Dinan TG, Quigley EM, Ahmed SM, Scully P, O'Brien S, O’Mahony L, O'Mahony S, Shanahan F \& Keeling PW 2006 Hypothalamicpituitary-gut axis dysregulation in irritable bowel syndrome: plasma cytokines as a potential biomarker? Gastroenterology 130 304-311. (https://doi.org/10.1053/j.gastro.2005.11.033)

Dlugosz A, Nowak P, D'Amato M, Mohammadian Kermani G, Nystrom J, Abdurahman S \& Lindberg G 2015 Increased serum levels of lipopolysaccharide and antiflagellin antibodies in patients with diarrhea-predominant irritable bowel syndrome. Neurogastroenterology and Motility 27 1747-1754. (https://doi.org/10.1111/nmo.12670)

Gareau MG, Jury J \& Perdue MH 2007 Neonatal maternal separation of rat pups results in abnormal cholinergic regulation of epithelial 
permeability. American Journal of Physiology: Gastrointestinal and Liver Physiology 293 G198-G203. (https://doi.org/10.1152/ ajpgi.00392.2006)

Ghosh A, Birngruber T, Sattler W, Kroath T, Ratzer M, Sinner F \& Pieber TR 2014 Assessment of blood-brain barrier function and the neuroinflammatory response in the rat brain by using cerebral open flow microperfusion (cOFM). PLOS ONE 9 e98143. (https://doi. org/10.1371/journal.pone.0098143)

Gourcerol G, Wu SV, Yuan PQ, Pham H, Miampamba M, Larauche M, Sanders P, Amano T, Mulak A, Im E, et al. 2011 Activation of corticotropin-releasing factor receptor 2 mediates the colonic motor coping response to acute stress in rodents. Gastroenterology 1401586. e1586-1596.e1586. (https://doi.org/10.1053/j.gastro.2011.01.039)

He X, Cui LH, Wang XH, Yan ZH, Li C, Gong SD, Zheng Y, Luo Z \& Wang Y 2017 Modulation of inflammation by toll-like receptor 4/ nuclear factor-kappa B in diarrhea-predominant irritable bowel syndrome. Oncotarget 8 113957-113965. (https://doi.org/10.18632/ oncotarget.23045)

Hillhouse EW \& Grammatopoulos DK 2006 The molecular mechanisms underlying the regulation of the biological activity of corticotropinreleasing hormone receptors: implications for physiology and pathophysiology. Endocrine Reviews 27 260-286. (https://doi. org/10.1210/er.2005-0034)

Kanazawa M, Hongo M \& Fukudo S 2011 Visceral hypersensitivity in irritable bowel syndrome. Journal of Gastroenterology and Hepatology 26 (Supplement 3) 119-121. (https://doi.org/10.1111/j.14401746.2011.06640.x)

Kidd M, Gustafsson BI, Drozdov I \& Modlin IM 2009 IL1beta- and LPS-induced serotonin secretion is increased in EC cells derived from Crohn's disease. Neurogastroenterology and Motility 21 439-450. (https://doi.org/10.1111/j.1365-2982.2008.01210.x)

Kocak E, Akbal E, Koklu S, Ergul B \& Can M 2016 The colonic tissue levels of TLR2, TLR4 and nitric oxide in patients with irritable bowel syndrome. Internal Medicine 55 1043-1048. (https://doi.org/10.2169/ internalmedicine.55.5716)

Larauche M, Gourcerol G, Wang L, Pambukchian K, Brunnhuber S, Adelson DW, Rivier J, Million M \& Taché Y 2009 Cortagine, a CRF1 agonist, induces stresslike alterations of colonic function and visceral hypersensitivity in rodents primarily through peripheral pathways. American Journal of Physiology: Gastrointestinal and Liver Physiology 297 G215-G227. (https://doi.org/10.1152/ajpgi.00072.2009)

Larauche M, Mulak A \& Taché Y 2012 Stress and visceral pain: from animal models to clinical therapies. Experimental Neurology 233 49-67. (https://doi.org/10.1016/j.expneurol.2011.04.020)

Lewis K, Li C, Perrin MH, Blount A, Kunitake K, Donaldson C, Vaughan J, Reyes TM, Gulyas J, Fischer W, et al. 2001 Identification of urocortin III, An additional member of the corticotropin-releasing factor (CRF) family with high affinity for the CRF2 receptor. PNAS 98 7570-7575. (https://doi.org/10.1073/pnas.121165198)

Liebregts T, Adam B, Bredack C, Roth A, Heinzel S, Lester S, DownieDoyle S, Smith E, Drew P, Talley NJ, et al. 2007 Immune activation in patients with irritable bowel syndrome. Gastroenterology 132 913-920. (https://doi.org/10.1053/j.gastro.2007.01.046)

Liu S, Ren W, Qu MH, Bishop GA, Wang GD, Wang XY, Xia Y \& Wood JD 2010 Differential actions of urocortins on neurons of the myenteric division of the enteric nervous system in guinea pig distal colon. British Journal of Pharmacology 159 222-236. (https://doi.org/10.1111/ j.1476-5381.2009.00516.x)

Martínez V, Rivier J, Wang L \& Taché Y 1997 Central injection of a new corticotropin-releasing factor (CRF) antagonist, astressin, blocks CRFand stress-related alterations of gastric and colonic motor function. Journal of Pharmacology and Experimental Therapeutics 280 754-760.

Mawe GM, Coates MD \& Moses PL 2006 Review article: intestinal serotonin signalling in irritable bowel syndrome. Alimentary Pharmacology and Therapeutics 23 1067-1076. (https://doi. org/10.1111/j.1365-2036.2006.02858.x)
McCurdy JD, Lin TJ \& Marshall JS 2001 Toll-like receptor 4-mediated activation of murine mast cells. Journal of Leukocyte Biology $\mathbf{7 0}$ 977-984.

Mearin F, Lacy BE, Chang L, Chey WD, Lembo AJ, Simren M \& Spiller R 2016 Bowel disorders. Gastroenterology 150 1393-1407. (https://doi. org/10.1053/j.gastro.2016.02.031)

Million M, Wang L, Wang Y, Adelson DW, Yuan PQ, Maillot C, Coutinho SV, McRoberts JA, Bayati A, Mattsson H, et al. $2006 \mathrm{CRF}_{2}$ receptor activation prevents colorectal distension induced visceral pain and spinal ERK1/2 phosphorylation in rats. Gut 55 172-181. (https://doi.org/10.1136/gut.2004.051391)

Nebot-Vivinus M, Harkat C, Bzioueche H, Cartier C, Plichon-Dainese R, Moussa L, Eutamene H, Pishvaie D, Holowacz S, Seyrig C, et al. 2014 Multispecies probiotic protects gut barrier function in experimental models. World Journal of Gastroenterology 20 6832-6843. (https://doi. org/10.3748/wjg.v20.i22.6832)

Ness TJ \& Gebhart GF 1988 Colorectal distension as a noxious visceral stimulus: physiologic and pharmacologic characterization of pseudaffective reflexes in the rat. Brain Research 450 153-169. (https://doi.org/10.1016/0006-8993(88)91555-7)

Nozu T \& Okumura T 2015 Corticotropin-releasing factor receptor type 1 and type 2 interaction in irritable bowel syndrome. Journal of Gastroenterology 50 819-830. (https://doi.org/10.1007/s00535-0151086-8)

Nozu T, Tsuchiya Y, Kumei S, Takakusaki K \& Okumura T 2013 Peripheral corticotropin-releasing factor (CRF) induces stimulation of gastric contractions in freely moving conscious rats: role of CRF receptor types 1 and 2. Neurogastroenterology and Motility 25 190-197. (https:// doi.org/10.1111/nmo.12050)

Nozu T, Takakusaki K \& Okumura T 2014 A balance theory of peripheral corticotropin-releasing factor receptor type 1 and type 2 signaling to induce colonic contractions and visceral hyperalgesia in rats. Endocrinology 155 4655-4664. (https://doi.org/10.1210/en.2014-1421)

Nozu T, Miyagishi S, Kumei S, Nozu R, Takakusaki K \& Okumura T $2017 a$ Lovastatin inhibits visceral allodynia and increased colonic permeability induced by lipopolysaccharide or repeated water avoidance stress in rats. European Journal of Pharmacology $\mathbf{8 1 8}$ 228-234. (https://doi.org/10.1016/j.ejphar.2017.10.056)

Nozu T, Miyagishi S, Nozu R, Takakusaki K \& Okumura T 2017b Lipopolysaccharide induces visceral hypersensitivity: role of interleukin-1, interleukin-6, and peripheral corticotropin-releasing factor in rats. Journal of Gastroenterology 52 72-80. (https://doi. org/10.1007/s00535-016-1208-y)

Nozu T, Miyagishi S, Nozu R, Takakusaki K \& Okumura T 2017c Repeated water avoidance stress induces visceral hypersensitivity; role of IL-1, IL-6 and peripheral corticotropin-releasing factor. Journal of Gastroenterology and Hepatology 32 1958-1965. (https://doi. org/10.1111/jgh.13787)

Obreja O, Rathee PK, Lips KS, Distler C \& Kress M 2002 IL-1 beta potentiates heat-activated currents in rat sensory neurons: involvement of IL-1RI, tyrosine kinase, and protein kinase C. FASEB Journal 16 1497-1503. (https://doi.org/10.1096/fj.02-0101com)

O'malley D, Julio-Pieper M, Gibney SM, Gosselin RD, Dinan TG \& Cryan JF 2010 Differential stress-induced alterations of colonic corticotropin-releasing factor receptors in the Wistar Kyoto rat. Neurogastroenterology and Motility 22 301-311. (https://doi. org/10.1111/j.1365-2982.2009.01412.x)

Ortiz-Lucas M, Saz-Peiro P \& Sebastian-Domingo JJ 2010 Irritable bowel syndrome immune hypothesis. Part two: the role of cytokines. Revista Española de Enfermedades Digestivas 102 711-717.

Overman EL, Rivier JE \& Moeser AJ 2012 CRF induces intestinal epithelial barrier injury via the release of mast cell proteases and TNF-alpha. PLOS ONE 7 e39935. (https://doi.org/10.1371/journal.pone.0039935)

Perrin MH \& Vale WW 1999 Corticotropin releasing factor receptors and their ligand family. Annals of the New York Academy of Sciences $\mathbf{8 8 5}$ 312-328. (https://doi.org/10.1111/j.1749-6632.1999.tb08687.x) 
Piche T 2014 Tight junctions and IBS - the link between epithelial permeability, low-grade inflammation, and symptom generation? Neurogastroenterology and Motility 26 296-302. (https://doi. org/10.1111/nmo.12315)

Reyes TM, Lewis K, Perrin MH, Kunitake KS, Vaughan J, Arias CA, Hogenesch JB, Gulyas J, Rivier J, Vale WW, et al. 2001 Urocortin II: a member of the corticotropin-releasing factor (CRF) neuropeptide family that is selectively bound by type 2 CRF receptors. PNAS 98 2843-2848. (https://doi.org/10.1073/pnas.051626398)

Santos J, Saunders PR, Hanssen NP, Yang PC, Yates D, Groot JA \& Perdue MH 1999 Corticotropin-releasing hormone mimics stressinduced colonic epithelial pathophysiology in the rat. American Journal of Physiology: Gastrointestinal and Liver Physiology $27 \mathbf{7}$ G391-G399. (https://doi.org/10.1152/ajpgi.1999.277.2.G391)

Santos J, Yates D, Guilarte M, Vicario M, Alonso C \& Perdue MH 2008 Stress neuropeptides evoke epithelial responses via mast cell activation in the rat colon. Psychoneuroendocrinology 33 1248-1256. (https://doi.org/10.1016/j.psyneuen.2008.07.002)

Scully P, McKernan DP, Keohane J, Groeger D, Shanahan F, Dinan TG \& Quigley EM 2010 Plasma cytokine profiles in females with irritable bowel syndrome and extra-intestinal co-morbidity. American Journal of Gastroenterology 105 2235-2243. (https://doi.org/10.1038/ajg.2010.159)

Suzuki T, Yoshinaga N \& Tanabe S 2011 Interleukin-6 (IL-6) regulates claudin-2 expression and tight junction permeability in intestinal epithelium. Journal of Biological Chemistry 286 31263-31271. (https:// doi.org/10.1074/jbc.M111.238147)

Taché Y \& Brunnhuber S 2008 From Hans Selye's discovery of biological stress to the identification of corticotropin-releasing factor signaling pathways: implication in stress-related functional bowel diseases. Annals of the New York Academy of Sciences 1148 29-41. (https://doi. org/10.1196/annals.1410.007)

Taché Y, Martínez V, Wang L \& Million M $2004 \mathrm{CRF}_{1}$ receptor signaling pathways are involved in stress-related alterations of colonic function and viscerosensitivity: implications for irritable bowel syndrome. British Journal of Pharmacology 141 1321-1330. (https://doi. org/10.1038/sj.bjp.0705760)

Taché Y, Kiank C \& Stengel A 2009 A role for corticotropin-releasing factor in functional gastrointestinal disorders. Current Gastroenterology Reports 11 270-277. (https://doi.org/10.1007/s11894-009-0040-4)

Teitelbaum AA, Gareau MG, Jury J, Yang PC \& Perdue MH 2008 Chronic peripheral administration of corticotropin-releasing factor causes colonic barrier dysfunction similar to psychological stress. American Journal of Physiology: Gastrointestinal and Liver Physiology 295 G452-G459. (https://doi.org/10.1152/ajpgi.90210.2008)

Tsatsanis C, Androulidaki A, Alissafi T, Charalampopoulos I, Dermitzaki E, Roger T, Gravanis A \& Margioris AN 2006 Corticotropin-releasing factor and the urocortins induce the expression of TLR4 in macrophages via activation of the transcription factors PU.1 and AP-1. Journal of Immunology 176 1869-1877. (https://doi.org/10.4049/ jimmunol.176.3.1869)

Vaughan J, Donaldson C, Bittencourt J, Perrin MH, Lewis K, Sutton S, Chan R, Turnbull AV, Lovejoy D \& Rivier C 1995 Urocortin, a mammalian neuropeptide related to fish urotensin I and to corticotropin-releasing factor. Nature 378 287-292. (https://doi. org/10.1038/378287a0)

Wu SV, Yuan PQ, Lai J, Wong K, Chen MC, Ohning GV \& Taché Y 2011 Activation of Type $1 \mathrm{CRH}$ receptor isoforms induces serotonin release from human carcinoid BON-1N cells: an enterochromaffin cell model. Endocrinology 152 126-137. (https://doi.org/10.1210/en.2010-0997)

Yu Y, Liu ZQ, Liu XY, Yang L, Geng XR, Yang G, Liu ZG, Zheng PY \& Yang PC 2013 Stress-derived corticotropin releasing factor breaches epithelial endotoxin tolerance. PLOS ONE 8 e65760. (https://doi. org/10.1371/journal.pone.0065760)

Yuan PQ, Wu SV, Wang L \& Taché Y 2010 Corticotropin releasing factor in the rat colon: expression, localization and upregulation by endotoxin. Peptides 31 322-331. (https://doi.org/10.1016/j. peptides.2009.11.012)

Yuan PQ, Wu SV \& Taché Y 2012 Urocortins and CRF type 2 receptor isoforms expression in the rat stomach are regulated by endotoxin: role in the modulation of delayed gastric emptying. American Journal of Physiology: Gastrointestinal and Liver Physiology 303 G20-G31. (https://doi.org/10.1152/ajpgi.00547.2011)

Yuan PQ, Wu SV, Pothoulakis C \& Tache Y 2016 Urocortins and CRF receptor type 2 variants in the male rat colon: gene expression and regulation by endotoxin and anti-inflammatory effect. American Journal of Physiology: Gastrointestinal and Liver Physiology $\mathbf{3 1 0}$ G387-G398. (https://doi.org/10.1152/ajpgi.00337.2015)

Yue H, Bin L, Chaoying C, Meng Z, Meng L \& Xi W 2017 Potential regulatory effects of corticotropin-releasing factor on tight junctionrelated intestinal epithelial permeability are partially mediated by CK8 upregulation. Cellular Physiology and Biochemistry 44 1161-1173. (https://doi.org/10.1159/000485420)

Received in final form 17 August 2018

Accepted 22 August 2018

Accepted Preprint published online 23 August 2018 (c) 2018 Society for Endocrinology Published by Bioscientifica Ltd. Printed in Great Britain 